\title{
Stereotactic Ablative Radiotherapy for the Management of Liver Metastases from Neuroendocrine Neoplasms: A Preliminary Study
}

\author{
John Monte Hudson ${ }^{a}$ Hans Tse-Kan Chung ${ }^{a}$ William Chu ${ }^{a}$ \\ Amandeep Taggar ${ }^{a}$ Laura Ellen Davis ${ }^{b}$ Julie Hallet ${ }^{c}$ Calvin How Lim Law ${ }^{c}$ \\ Simron Singh ${ }^{d}$ Sten Myrehaug ${ }^{a}$ \\ aDepartment of Radiation Oncology, Odette Cancer Centre, Sunnybrook Health Sciences Centre, University of \\ Toronto, Toronto, ON, Canada; ${ }^{b}$ Department of Epidemiology, Biostatistics and Occupational Health, McGill \\ University, Montreal, QC, Canada; 'Department of Surgical Oncology, Odette Cancer Centre, Sunnybrook Health \\ Sciences Centre, University of Toronto, Toronto, ON, Canada; ${ }^{d}$ Division of Medical Oncology, Odette Cancer Centre, \\ Sunnybrook Health Sciences Centre, University of Toronto, Toronto, ON, Canada
}

\section{Keywords}

Stereotactic ablative radiotherapy · Radiation · Liver metastases - Neuroendocrine

\begin{abstract}
Introduction: Liver metastases are common in patients with neuroendocrine neoplasms. The role of stereotactic ablative radiotherapy (SABR) is not well understood in this population. Objective: The objective of this study was to evaluate the safety and efficacy of SABR in treating well-differentiated neuroendocrine liver metastases (WD-NELM). Methods: A retrospective review of patients with WD-NELM treated with SABR was conducted between January 2015 and July 2019. Demographic, treatment, and clinical/radiographic followup data were abstracted. RECIST 1.1 criteria were applied to each individual target to evaluate the response to treatment. Local control (LC) and progression-free survival (PFS) were determined using the Kaplan-Meier methodology. Toxicity was reported according to the CTCAE v5.0. Results: Twentyfive patients with a total of 53 liver metastases treated with SABR were identified. Most patients (68\%) had midgut tumors, were grade 2 (80\%), and had high-volume intrahepatic and/or extrahepatic disease (76\%). The median number of
\end{abstract}

karger@karger.com www.karger.com/nen

Karger $\frac{1}{\%}$
C 2021 The Author(s)

Published by S. Karger AG, Basel

This is an Open Access article licensed under the Creative Commons Attribution-NonCommercial-4.0 International License (CC BY-NC) (http://www.karger.com/Services/OpenAccessLicense), applicable to the online version of the article only. Usage and distribution for commercial purposes requires written permission.

liver metastases treated was 2, with a median size of $2.5 \mathrm{~cm}$. The median radiation dose delivered was $50 \mathrm{~Gy} / 5$ fractions. The median follow-up was 14 months; 24 of the 25 patients were alive at the time of analysis. The objective response rate was $32 \%$, with improvement or stability in $96 \%$ of lesions treated. The median time to best response was 9 months. The 1-year LC and PFS were 92 and 44\%, respectively. No grade 3/4 acute or late toxicity was identified. Conclusions: Liver SABR is a safe and promising means of providing LC for WD-NELM. This treatment modality should be evaluated in selected patients in concert with strategies to manage systemic disease.

(c) 2021 The Author(s)

Published by S. Karger AG, Basel

\section{Introduction}

Neuroendocrine neoplasms (NENs) are diverse malignancies that vary in terms of histology and clinical aggressiveness. The 2017 World Health Organization (WHO) system classifies these tumors into grades based on the differentiation status and mitotic/Ki-67 proliferation indices [1]. Low-grade tumors may remain indolent for years, whereas poorly differentiated grade III neuroendo- 
crine carcinoma is typically associated with poor disease control and limited survival. Given the favorable natural history of well-differentiated grade 1 and 2 tumors, patients may expect to have prolonged survival even in the setting of metastatic disease. Treatment modalities must therefore maximize tumor control, maintain quality of life, and minimize treatment-related side effects.

At diagnosis, $20.8 \%$ of patients had de novo metastatic disease, with another $38 \%$ of patients subsequently developed metastases during their disease course, with the liver being the most common site of spread $[2,3]$. Presentation of metastatic disease in the liver varies from solitary disease to an extensive miliary pattern [4]. Treatment options are dependent on the burden of disease, presence of functional symptoms, and patient performance status.

Somatostatin analogs (SSA) are a well-tolerated treatment for metastatic NENs that provide both functional and systemic cytostatic control $[5,6]$; however, concurrent liver-directed therapies are often utilized to improve disease control and survival [7]. Surgical resection provides excellent tumoral and biochemical control but remains reserved for patients with low-volume liver metastases or with a significant functional burden [8]. Alternative treatment modalities are available for patients with more diffuse disease, who are technically unresectable, and/or who have significant competing medical comorbidities. Transarterial (chemo)embolization (TAE) has demonstrated effectiveness in both tumor and biochemical control for patients with diffuse liver disease $[9,10]$, although the majority of patients develop post-embolization syndrome (fever, malaise, pain, and nausea) with a major complication rate approaching 5\% [11]. Peptide receptor radionuclide therapy is also indicated for disease progression following SSA treatment [12]; however, more locally ablative approaches may be more appropriate for low-volume liver-only disease. Radiofrequency ablation (RFA) provides excellent control of small liver metastases with low toxicity but may be limited by the size and location of metastases [9]. Due to these restrictions, stereotactic ablative radiotherapy (SABR), an additional option, is used for treating progressive liver metastases.

SABR, defined as ultra-high dose per fraction radiation that is delivered to small volumes, is becoming increasingly utilized for treating primary and metastatic solid tumors. Prospective series evaluating treatment of liver metastases from any histology (predominantly colorectal) report a 1-year local control (LC) in the range of $70-90 \%$ with very low rates of acute and late toxicities $[13,14]$. This treatment is now an established option for the management of unresectable colorectal liver metasta- ses and hepatocellular carcinoma [15]. NENs have historically been considered radioresistant due to modest responses seen with conventionally delivered radiation treatment [16]. Current data evaluating the impact of modern stereotactic radiation therapy for neuroendocrine liver metastases (NELM) are limited to case reports. The current study outlines the experience from 2015 to 2019 at the Susan Leslie Clinic for Neuroendocrine Tumors at the Odette Cancer Centre, Sunnybrook Health Sciences Centre, in the treatment of liver metastases from well-differentiated grade 1 or 2 NENs with SABR.

\section{Materials and Methods}

An institutional REB-approved retrospective chart review of patients with well-differentiated NELM treated with SABR was performed between January 2015 and July 2019. Demographics, treatment details, and clinical/radiographic follow-up data were abstracted from the patients' clinical and radiation planning records.

Each patient was assessed in the Susan Leslie Clinic for Neuroendocrine Tumors, a multidisciplinary clinic dedicated to the management of neuroendocrine tumors. In this clinic, all patients are concomitantly assessed by physicians specialized in NET from surgical oncology, medical oncology, radiation oncology, and endocrinology and when appropriate further presented at tumor board with radiology, interventional radiology, and pathology [17]. All patients had progressed on SSA therapy and/or everolimus and were deemed not a candidate for surgical resection or other localized therapy (based upon extent of disease, size/location of disease, progression post-local therapy, patient comorbidities, or patient preference). Patients with $\leq 5$ systemic metastases, as defined by multiphasic CT and liver MRI, were classified as being oligometastatic; those with more advanced systemic disease but with $\leq 4$ NELM progressing on therapy were classified as being oligoprogressive. Representative images demonstrating this classification are shown in Figure 1.

Patients received radiotherapy according to institutional guidelines using abdominal compression or active breathing control for liver motion management and image-guided, intensity-modulated or volumetric-modulated arc therapy. Radiation was prescribed to ensure coverage by $>95 \%$ of the prescription dose to the planning target volume, respecting dose constraints to normal liver parenchyma and adjacent organs at risk. Representative treatment dose distribution is shown in Figure 2. All patients were premedicated with a prophylactic $5-\mathrm{HT}_{3}$ receptor antagonist for radiation-induced nausea prevention prior to each treatment delivery. Patients were evaluated clinically during radiation therapy, at 28 days posttherapy and then every 3 months following completion of radiation therapy. All patients underwent multiphasic CT imaging on follow-up every 3 months following treatment and evaluated with the same criteria as RECIST 1.1, but applied to each individual target treated. Pseudoprogression was defined as initial increase in size of lesion in the absence of clinical symptoms with subsequent decrease in size on serial imaging [18].

Descriptive statistics were performed, and variables were presented categorically as proportions or continuously using medians. 

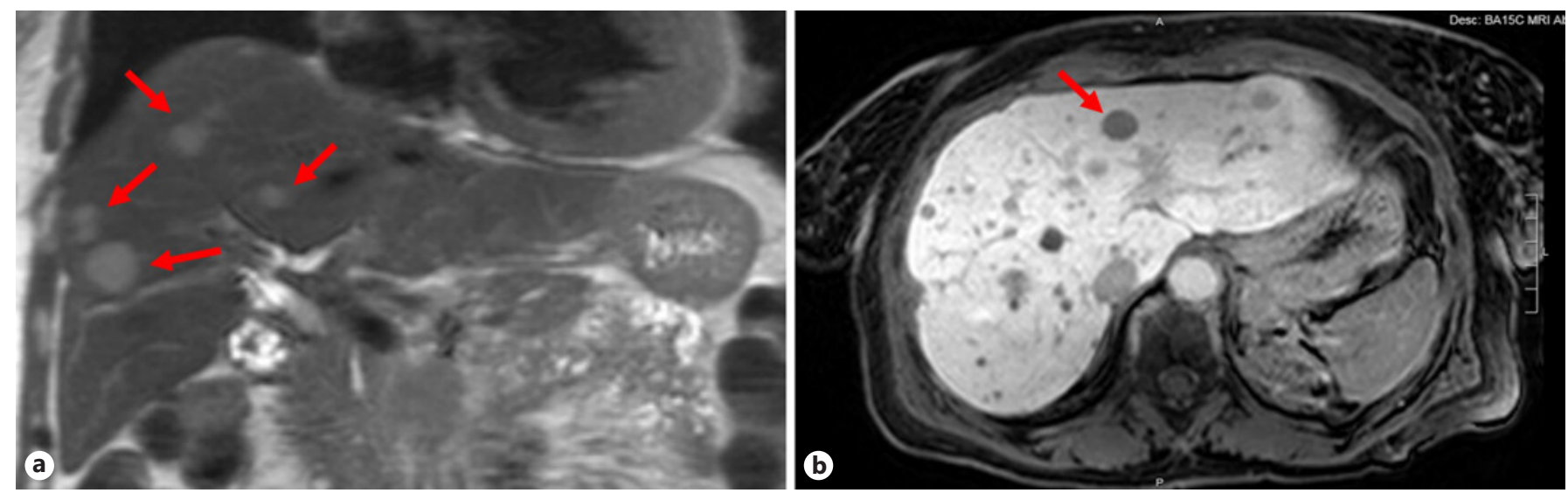

Fig. 1. Representative images describing oligometastatic and oligoprogressive classifications. a Oligometastatic disease - 4 metastases in liver (arrows), all treated with SABR. b Oligoprogressive disease - innumerable liver metastases. One growing metastases treated with SABR (arrow). SABR, stereotactic ablative radiotherapy.

One-year LC and systemic control were calculated. Toxicity was evaluated retrospectively and reported as per the CTCAE v5.0 criteria. R Studio version 1.1.463 was used for all statistical analyses.

\section{Results}

Twenty-five patients with a total of 53 individual liver metastases treated with SABR were identified. The median follow-up was 14 months (range 2-54 months). Twenty-four of the 25 patients were still alive at the time of data analysis. Patient demographics are reported in Table 1. Most patients (68\%) had midgut tumors (small bowel and pancreas), were grade $2(80 \%)$, and were treated for oligoprogressive disease (76\%). All patients had progressed on SSA, of which 2 had also progressed on everolimus. Fifteen patients (64\%) had prior local therapy to the liver: surgery (9), liver-directed therapy (6), or both (2). Almost all patients (96\%) remained on SSA despite having radiographic disease progression.

Radiation treatment details are outlined in Table 2. The median number of liver metastases treated per patient was 2 (range: $1-4$ ), with a median size of $2.5 \mathrm{~cm}$ (range 0.7-9.7 cm). The median radiation dose delivered was $50 \mathrm{~Gy} / 5$ fractions (range $25-60 \mathrm{~Gy} / 3$ fractions), with a median biologically effective dose $\left(\mathrm{BED}_{10}\right)$ of 100 (range 39-180).

Of the 53 treated metastases, 3 patients with 6 total metastases were defined as stable disease due to radiation treatment effects that either obscured accurate size definition or led to pseudoprogression (defined as an initial increase in size of the lesion but subsequent decrease on

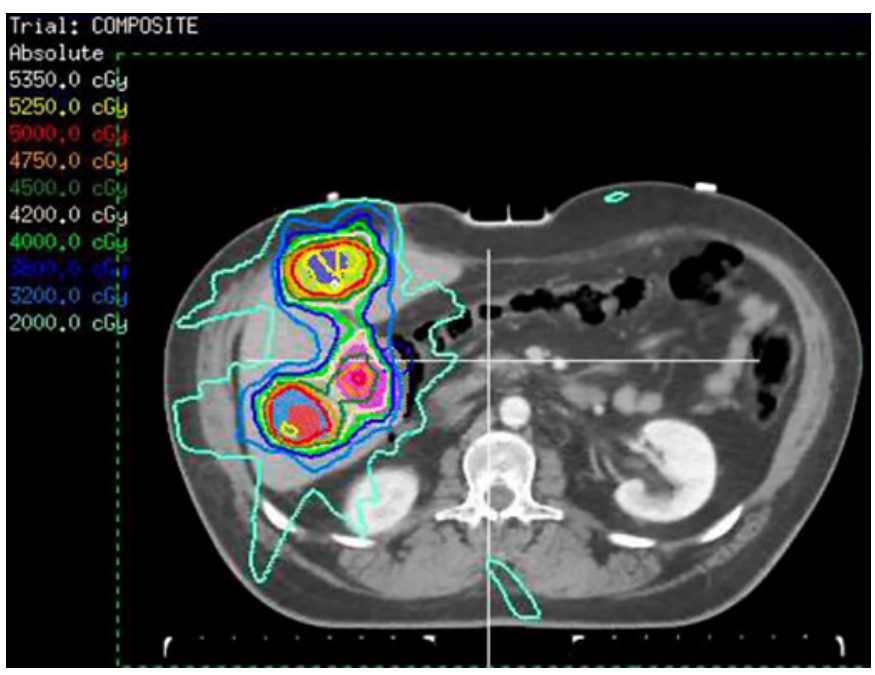

Fig. 2. Representative dose distribution of multi-target SABR for 3 treated liver metastases. Differential radiation dose prescribed to each target is dependent on proximity to adjacent organs at risk. SABR, stereotactic ablative radiotherapy.

serial imaging). The evaluated overall response was complete response $=2$, partial response $=13$, stable disease $=$ 30 , and progressive disease $=2$. The best treatment response according to changes in axial diameter was $-100 \%$ (median $-16 \%$, range -100 to $47 \%$ ), graphically represented in Figure 3. The objective response rate was 32\%, seen in 12 patients. Initial disease improvement or stability was seen in $96 \%$ of all lesions treated. The median time to best response was 9 months (range 3-16 months). LC at 1 year was $92 \%$ (CI $0.847-0.999 \%)$. Systemic progression-free survival (PFS) at 1 year was $44 \%$ (CI $0.28-$ 
Table 1. Patient demographics

\begin{tabular}{|c|c|}
\hline Variable & $N=25$ \\
\hline \multicolumn{2}{|l|}{ Sex } \\
\hline Female & 14 \\
\hline Male & 11 \\
\hline Median age (range) & $70(46-88)$ \\
\hline \multicolumn{2}{|l|}{ Histology } \\
\hline Small bowel & 8 \\
\hline Duodenum & 2 \\
\hline Pancreas & 7 \\
\hline Colorectal & 4 \\
\hline Lung & 3 \\
\hline Renal & 1 \\
\hline \multicolumn{2}{|l|}{ Grade } \\
\hline 1 & 5 \\
\hline $2 *$ & 20 \\
\hline \multicolumn{2}{|l|}{ Metastases treated per patient, $n$} \\
\hline 1 & 10 \\
\hline 2 & 6 \\
\hline 3 & 5 \\
\hline 4 & 4 \\
\hline \multicolumn{2}{|l|}{ All sites of metastatic disease treated } \\
\hline Yes (oligometastatic disease) & 6 \\
\hline No (oligoprogressive disease) & 19 \\
\hline \multicolumn{2}{|l|}{ Concurrent SSA use } \\
\hline Yes & 24 \\
\hline No & 1 \\
\hline \multicolumn{2}{|l|}{ Prior liver surgery } \\
\hline Yes & 9 \\
\hline No & 16 \\
\hline \multicolumn{2}{|l|}{ Prior liver-directed therapy } \\
\hline Yes & 6 \\
\hline No & 19 \\
\hline
\end{tabular}

SSA, somatostatin analogs. * Atypical lung carcinoid classified as grade 2 .

$0.70 \%)$. Local progression was only observed in patients with grade 2 histology.

Table 3 outlines identified acute and late toxicities. Three patients (12\%) experienced acute grade 2 fatigue, and $4 \%$ experienced grade 2 nausea. One patient (4\%) continued to have late grade 2 fatigue. No patients experienced any grade 3 or 4 acute or late toxicity.

\section{Discussion/Conclusion}

The potentially indolent course of well-differentiated NEN necessitates a treatment that maximizes disease control, maintains quality of life, and minimizes acute and chronic side effects of therapy. As there are no large
Table 2. Liver metastasis treatment characteristics

\begin{tabular}{lc}
\hline Variable & $\begin{array}{c}\text { Total liver metastases } \\
\text { treated }(n=53)\end{array}$ \\
\hline $\begin{array}{l}\text { Median size of metastases (range) } \\
\text { Size grouping of metastases, cm }\end{array}$ & $2.5 \mathrm{~cm}(0.7-9.7 \mathrm{~cm})$ \\
$>1.0$ & 3 \\
$1.0-1.9$ & 14 \\
$2-2.9$ & 19 \\
$3-3.9$ & 5 \\
$>4$ & 12 \\
Median biological equivalent dose (range) & $100 \mathrm{~Gy} / 0(39-180)$ \\
Radiation dose/fractionation & 2 \\
30 Gy/5 & 3 \\
35 Gy/5 & 10 \\
40 Gy/5 & 6 \\
45 Gy/5 & 20 \\
50 Gy/5 & 3 \\
60 Gy/5 & 2 \\
Other & 7 \\
\hline
\end{tabular}

comparative clinical trials that have evaluated systemic and liver-directed therapies, treatment selection is best determined by a multidisciplinary team that weighs the benefits and toxicity of each therapy in the context of the patient's goals, the burden of functional symptoms, and the pattern of metastatic disease [19].

Surgical resection is a first-line option for functional tumors to reduce hormonal burden and should also be considered for cytoreduction of low-volume disease in properly selected patients $[8,19,20]$. However, patient or technical factors must be considered, given an acute surgical morbidity rate of $18 \%$ [8]. TAE is an alternative treatment for diffuse disease and/or symptomatic hormone production that has early tumor response and control rates of $50-66$ and $\sim 80 \%$, respectively. It is associated with a serious acute adverse event rate upward of $8 \%$ and grade 3 toxicity ranging from 0 to $25 \%$ [21-23]. Similarly, treatment with selective internal radiation therapy (SIRT) is also effective with a reported tumor response of $\sim 55 \%$ and control at $85-90 \%$, with acute side effects seen in 30\% of patients and grade 3 toxicity in $10 \%$ of patients [24,25]. RFA is another well-tolerated liver-directed therapy effective in decreasing hormonal burden with reported tumor control rates of $60-80 \%$ and a modest complication rate of $\sim 10 \%[9,26]$. Peptide receptor radionuclide therapy may also be utilized in patients who have progressed on SSA [12]; however, it remains unclear whether patients with liver-only or low-volume oligometastatic dis- 
Fig. 3. Maximum percent change in linear diameter per evaluable liver metastases after SABR. Targets in red, blue, green, and black represent $\mathrm{PD}, \mathrm{SD}, \mathrm{PR}$, and $\mathrm{CR}$, respectively. SABR, stereotactic ablative radiotherapy; $\mathrm{PD}$, progressive disease; $\mathrm{SD}$; stable disease; $\mathrm{PR}$, partial response; $\mathrm{CR}$, complete response.

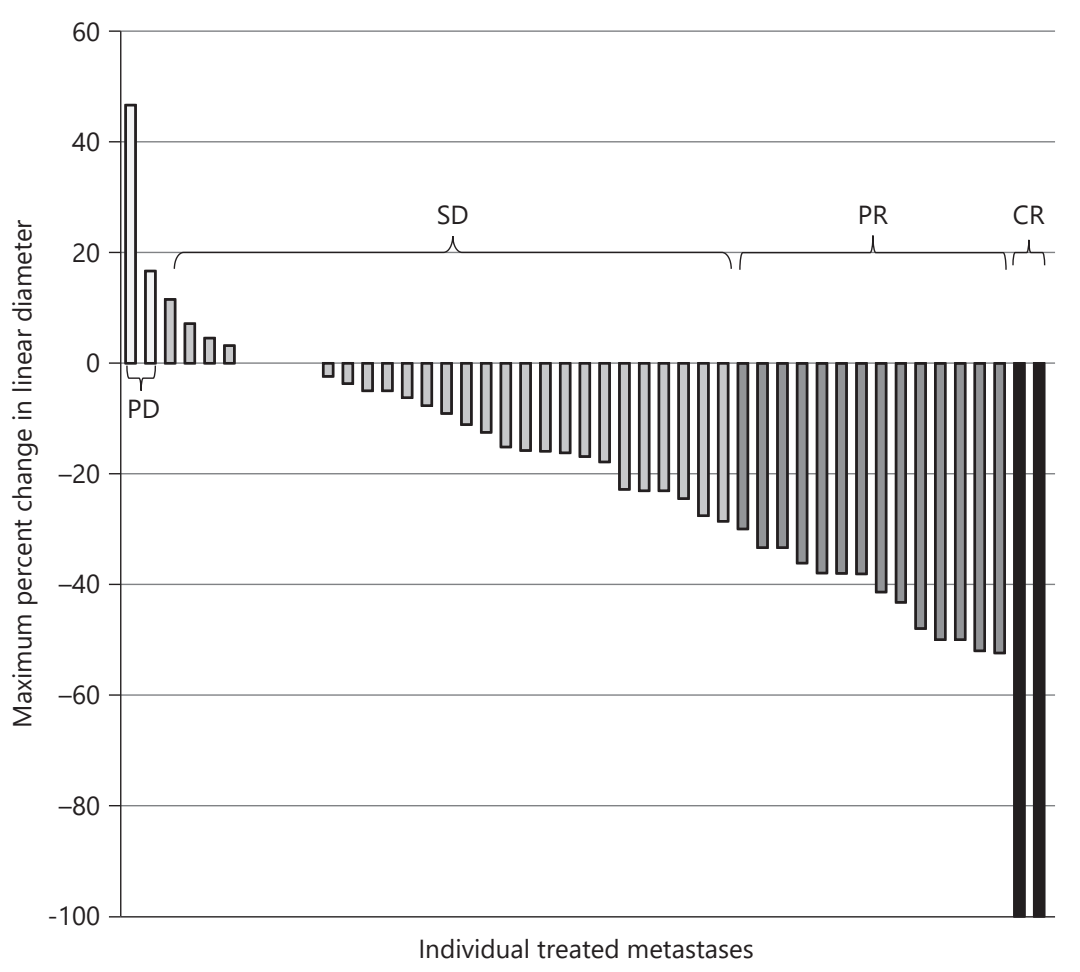

ease would benefit from a more targeted ablative approach.

The ENETS Consensus Guidelines for managing liver metastases recommend ablation (RFA, TAE, or SIRT) for low-volume liver metastases [19]. Historically, radiation has not been considered, likely due to initial experience using outdated techniques and dose/fractionation tailored for widespread metastatic disease [27]. Contemporary studies utilizing modern radiation techniques have demonstrated radiographic and clinical response to primary and metastatic disease $[16,28,29]$. Radiobiological models utilize the alpha/beta ratio to determine the response of tumors to varied dose/fraction radiation schemes; most rapidly growing histologies will have an alpha/beta value of $\sim 10$, while slower growing tumors will have a lower value and thus be more responsive to high-dose per fraction treatment [30]. Given the overall low proliferative rate of neuroendocrine tumors, compared to conventional radiation treatment, the use of SABR is predicted to be more effective. This premise is strengthened by a multigene expression index for radiosensitivity correlated with response to SABR for liver metastases [31], in which small bowel neuroendocrine malignancies were predicted to be highly radiosensitive, whereas pancreatic and large bowel
Table 3. Radiation-related toxicity

\begin{tabular}{|c|c|c|c|}
\hline Acute toxicity & $\begin{array}{l}\text { Incidence } \\
(n=25)\end{array}$ & $\begin{array}{l}\text { Late toxicity } \\
(n=25)\end{array}$ & $\begin{array}{l}\text { Incidence } \\
(n=25)\end{array}$ \\
\hline Fatigue & & Fatigue & \\
\hline Grade 0 & $18(72 \%)$ & Grade 0 & $23(92 \%)$ \\
\hline Grade 1 & $4(16 \%)$ & Grade 1 & $1(4 \%)$ \\
\hline Grade 2 & $3(12 \%)$ & Grade 2 & $1(4 \%)$ \\
\hline Grade 3+ & $0(0 \%)$ & Grade 3+ & $0(0 \%)$ \\
\hline Nausea & & Nausea & \\
\hline Grade 0 & $17(68 \%)$ & Grade 0 & $24(96 \%)$ \\
\hline Grade 1 & $7(28 \%)$ & Grade 1 & $1(4 \%)$ \\
\hline Grade 2 & $1(4 \%)$ & Grade 2 & $0(0 \%)$ \\
\hline Grade 3+ & $0(0 \%)$ & Grade 3+ & $0(0 \%)$ \\
\hline Abdominal pain & & Abdominal pain & \\
\hline Grade 0 & $23(92 \%)$ & Grade 0 & $25(100 \%)$ \\
\hline Grade 1 & $2(8 \%)$ & Grade 1 & $0(0 \%)$ \\
\hline Grade 2 & $0(0 \%)$ & Grade 2 & $0(0 \%)$ \\
\hline Grade 3+ & $0(0 \%)$ & Grade 3+ & $0(0 \%)$ \\
\hline Other & & Other & \\
\hline Grade 0 & $24(96 \%)$ & Grade 0 & $25(100 \%)$ \\
\hline Grade 1 & $1(4 \%)$ & Grade 1 & $0(0 \%)$ \\
\hline Grade 2 & $0(0 \%)$ & Grade 2 & $0(0 \%)$ \\
\hline Grade 3+ & $0(0 \%)$ & Grade 3+ & $0(0 \%)$ \\
\hline
\end{tabular}


neuroendocrine malignancies were predicted to have the same radiosensitivity as colorectal metastases. The largest series, to date, of patients with neuroendocrine tumors (of mixed histology, grade, and location) treated with highdose (defined as $\mathrm{BED}_{10}>40$ ) radiation to either locally advanced or metastatic disease demonstrated excellent LC (92\%) with median time to progression of 11 months [32]. Specific to liver metastases, an abstract by Bignardi et al. [33] described 2 patients with liver metastases from nonfunctional low-grade small bowel and pancreatic neuroendocrine tumors treated to 45-60 Gy, with reported LC greater than 40 months. A recent report by Ohri et al. [15] evaluating liver SABR for metastases of all histologies demonstrated improved control rates with $\mathrm{BED}_{10} \geq 100$ Gy. There was a nonsignificant trend toward improved LC with higher BED radiation in our series (data not shown), supporting that $\mathrm{BED}_{10} \geq 100 \mathrm{~Gy}$ should be considered when treating NELM.

The general slow growth rate of neuroendocrine disease must be considered when evaluating response on serial scans. In this series, patients were progressing on SSA therapy and the majority of patients had grade 2 disease, suggesting that observed LC is reflective of treatment effect as opposed to indolent behavior of disease. Our data demonstrating an objective response rate of $32 \%$ and 1 -year LC rate of $92 \%$ suggest that SABR is an effective treatment option to maximize LC with inherent patient advantages: minimally invasive, done as an outpatient, flexible with respect to tumor location, favorable side effect profile, and in the context of larger metastases, potentially superior and more cost-effective than RFA [34, 35]. Patients may have a prolonged disease course with NET; it is important to further develop the armamentarium for management of metastatic disease. Surgery should be the treatment of choice when it is appropriate and recommended. Given the excellent results of local therapy provided by RFA, TAE, and SIRT, future evaluation needs to be done to assess where SABR may be applied as an emerging LC strategy.

One important finding is the median time to maximal response of 9 months. This highlights a limitation of response evaluation criteria that rely on tumor dimensions, particularly when applied to therapies whose activity is not immediately reflected by change in tumor size. Traditional RECIST criteria have been criticized for their application in post-SABR response assessment [17]. The ablative nature of SABR therapy and its effect on the tumor microvasculature provide an opportunity to develop alternative response evaluation criteria sensitive to the tumor microenvironment. Dynamic contrast-enhanced and other functional imaging techniques are promising modalities under investigation for early response monitoring in a variety of solid tumor sites [36, 37]; we are prospectively evaluating alternative imaging response criteria in a subset of the patients currently being reported.

The role of SABR within the oligometastatic paradigm is intriguing. Emerging data in other histologies suggest that PFS and OS can be improved by treating all sites of metastatic disease with SABR in concert with standard of care systemic therapy $[38,39]$. Our results in liver metastases and recent case studies in primary pulmonary carcinoids $[40,41]$ demonstrate that SABR is an effective treatment modality for neuroendocrine cancers. Given the tolerability of SABR and SSA therapies, it can be hypothesized that clinical outcomes may be improved in patients with a low metastatic disease burden by combining SSAs and upfront SABR to all sites of disease, potentially delaying the transition to more toxic second-line therapy.

Limitations of this study include retrospective data collection, small sample size, and that it pre-dates the availability of Gallium-68 PET to evaluate the extent of disease. Given the increased sensitivity/specificity of Ga68 PET over CT and MRI $[42,43]$, there may have been occult disease within the liver that was not treated with ablative therapy, which may have impacted the overall PFS rates. However, this would be true for any local therapeutic option. Any future studies evaluating the role of SABR in the upfront setting would require Ga-68 PET to establish true oligometastatic disease presentations. However, given the nature of the Susan Leslie Clinic for Neuroendocrine Tumors at the Odette Cancer Centre, there are significant strengths: this is the largest series to date specific to treatment of liver metastases; all patients were reviewed by multidisciplinary team before being offered SABR, ensuring appropriateness of patient selection; all treatment plans were generated using a standardized departmental guidelines and underwent expert peer QA to ensure high-quality therapy; and all patients had clinical and radiographic follow-up at 1 treatment center to ensure consistent image acquisition/interpretation and patient evaluation.

This is the first series to specifically evaluate SABR as a treatment modality for well-differentiated NELM. SABR is a safe and promising treatment option for patients with limited volume disease; it may complement or provide an additional strategy for NELM alongside more established liver-directed therapies such as TAE, RFA, or SIRT. Further prospective studies are required to determine the optimal treatment modality and sequencing for patients with low-volume metastatic disease. 


\section{Statement of Ethics}

This retrospective study was approved and overseen by the Sunnybrook Research Institute Research Ethics Board (REB \#:1922019).

\section{Conflict of Interest Statement}

J.M.H. has no conflicts of interest to declare. H.T.-K.C. has no conflicts of interest to declare. W.C. has no conflicts of interest to declare. A.T. has no conflicts of interest to declare. L.E.D. has no conflicts of interest to declare. J.H.: Novartis, Ipsen, AAA, and Baxter. C.H.L.L.: Taiho, Ipsen, Novartis, AAA, Amgen, and Gilead. S.S.: Ipsen, Novartis, AAA, and EMD Serono. S.M.: Ipsen, Novartis, and AAA.

\section{Funding Sources}

No funding was received for this project.

\section{Author Contributions}

All authors provided substantial contributions. J.H.: analysis/ interpretation of data, manuscript creation, and final approval. L.D.: analysis/interpretation of data, manuscript creation, and final approval. H.T.-K.C., W.C., A.T., J.H., C.H.L.L., and S.S.: data acquisition, interpretation of data, manuscript creation, and final approval. S.M.: conception of work, data acquisition/interpretation, manuscript creation, and final approval.

\section{References}

1 Lloyd RV, Osamura RY, Klöppel G, Rosai J, Bosman FT, Jaffe ES, et al., editors. WHO classification of tumours of endocrine organs. Lyon: International Agency for Research on Cancer; 2017.

2 Hallet J, Law CH, Cukier M, Saskin R, Liu N, Singh S. Exploring the rising incidence of neuroendocrine tumors: a population-based analysis of epidemiology, metastatic presentation, and outcomes. Cancer. 2015;121(4):589-97.

3 Riihimaki M, Hemminki A, Sundquist K, Sundquist J, Hemminki K. The epidemiology of metastases in neuroendocrine tumors. Int J Cancer. 2016;139(12):2679-86.

4 Steinmuller T, Kianmanesh R, Falconi M, Scarpa A, Taal B, Kwekkeboom DJ, et al. Consensus guidelines for the management of patients with liver metastases from digestive (neuro)endocrine tumors: foregut, midgut, hindgut, and unknown primary. Neuroendocrinology. 2008;87(1):47-62.

5 Caplin ME, Pavel M, Ruszniewski P. Lanreotide in metastatic enteropancreatic neuroendocrine tumors. N Engl J Med. 2014;371(16) 1556-7.

6 Rinke A, Müller HH, Schade-Brittinger C, Klose KJ, Barth P, Wied M, et al. Placebo-controlled, double-blind, prospective, randomized study on the effect of octreotide LAR in the control of tumor growth in patients with metastatic neuroendocrine midgut tumors: a report from the PROMID study group. J Clin Oncol. 2009;27(28):4656-63.

7 Lewis MA, Hobday TJ. Treatment of neuroendocrine tumor liver metastases. Int J Hepatol. 2012;2012:973946.

8 Chan DL, Dixon M, Law CHL, Koujanian S, Beyfuss KA, Singh S, et al. Outcomes of cytoreductive surgery for metastatic low-grade neuroendocrine tumors in the setting of extrahepatic metastases. Ann Surg Oncol. 2018; 25(6):1768-74

9 de Baere T, Deschamps F, Tselikas L, Ducreux M, Planchard D, Pearson E, et al. GEP-NETS update: interventional radiology: role in the treatment of liver metastases from GEPNETs. Eur J Endocrinol. 2015;172(4):R15166.

10 Ruszniewski P, Rougier P, Roche A, Legmann P, Sibert A, Hochlaf S, et al. Hepatic arterial chemoembolization in patients with liver metastases of endocrine tumors. A prospective phase II study in 24 patients. Cancer. 1993; 71(8):2624-30.

11 Clark TW. Complications of hepatic chemoembolization. Semin Intervent Radiol. 2006; 23(2):119-25.

12 Strosberg J, El-Haddad G, Wolin E, Hendifar A, Yao J, Chasen B, et al. Phase 3 trial of (177) $\mathrm{Lu}$-dotatate for midgut neuroendocrine tumors. N Engl J Med. 2017;376(2):125-35.

13 Lee MT, Kim JJ, Dinniwell R, Brierley J, Lockwood G, Wong R, et al. Phase I study of individualized stereotactic body radiotherapy of liver metastases. J Clin Oncol. 2009;27(10): 1585-91.

14 Rule W, Timmerman R, Tong L, Abdulrahman R, Meyer J, Boike T, et al. Phase I doseescalation study of stereotactic body radiotherapy in patients with hepatic metastases. Ann Surg Oncol. 2011;18(4):1081-7.

15 Ohri N, Tome WA, Mendez Romero A, Miften M, Ten Haken RK, Dawson LA, et al. Local control after stereotactic body radiation therapy for liver tumors. Int J Radiat Oncol Biol Phys. 2018.

16 Chan DL, Thompson R, Lam M, Pavlakis N, Hallet J, Law C, et al. External beam radiotherapy in the treatment of gastroenteropancreatic neuroendocrine tumours: a systematic review. Clin Oncol. 2018;30(7):400-8.

17 Singh S, Law C. Multidisciplinary reference centers: the care of neuroendocrine tumors. Oncol Pract. 2010;6(6):e11-6.

18 Vernuccio F, Godfrey D, Meyer M, Williamson HV, Salama JK, Niedzwiecki D, et al. Local tumor control and patient outcome using stereotactic body radiation therapy for hepa- tocellular carcinoma: iRECIST as a potential substitute for traditional criteria. AJR Am J Roentgenol. 2019;213(6):1232-9.

19 Pavel M, O’Toole D, Costa F, Capdevila J, Gross D, Kianmanesh R, et al. ENETS consensus guidelines update for the management of distant metastatic disease of intestinal, pancreatic, bronchial neuroendocrine neoplasms (NEN) and NEN of unknown primary site. Neuroendocrinology. 2016;103(2):172-85.

20 Partelli S, Bartsch DK, Capdevila J, Chen J, Knigge U, Niederle B, et al. ENETS consensus guidelines for standard of care in neuroendocrine tumours: surgery for small intestinal and pancreatic neuroendocrine tumours. Neuroendocrinology. 2017;105(3):255-65.

21 Fiore F, Del Prete M, Franco R, Marotta V, Ramundo V, Marciello F, et al. Transarterial embolization (TAE) is equally effective and slightly safer than transarterial chemoembolization (TACE) to manage liver metastases in neuroendocrine tumors. Endocrine. 2014, 47(1):177-82.

22 Gupta S, Johnson MM, Murthy R, Ahrar K, Wallace MJ, Madoff DC, et al. Hepatic arterial embolization and chemoembolization for the treatment of patients with metastatic neuroendocrine tumors: variables affecting response rates and survival. Cancer. 2005; 104(8):1590-602.

23 Ruutiainen AT, Soulen MC, Tuite CM, Clark TW, Mondschein JI, Stavropoulos SW, et al. Chemoembolization and bland embolization of neuroendocrine tumor metastases to the liver. J Vasc Interv Radiol. 2007;18(7):847-55.

24 Barbier CE, Garske-Román U, Sandström M, Nyman R, Granberg D. Selective internal radiation therapy in patients with progressive neuroendocrine liver metastases. Eur J Nuc Med Mol Imaging. 2016;43(8):1425-31.

25 Jia Z, Wang W. Yttrium-90 radioembolization for unresectable metastatic neuroendocrine liver tumor: a systematic review. Eur J Radiol. 2018;100:23-9.
SABR for Liver Metastases from

Neuroendocrine Neoplasms
Neuroendocrinology 2022;112:153-160 DOI: $10.1159 / 000514914$ 
26 Mohan H, Nicholson P, Winter DC, O'Shea D, O’Toole D, Geoghegan J, et al. Radiofrequency ablation for neuroendocrine liver metastases: a systematic review. J Vasc Interv Radiol. 2015;26(7):935-e1.

27 Keane TJ, Rider WD, Harwood AR, Thomas GM, Cummings BJ. Whole abdominal radiation in the management of metastatic gastrointestinal carcinoid tumor. Int J Radiat Oncol Biol Phys. 1981;7(11):1519-21.

28 Guan M, He I, Luu M, David J, Gong J, Placencio-Hickok VR, et al. Palliative radiation therapy for bone metastases in neuroendocrine neoplasms. Adv Radiat Oncol. 2019 JulSept;4(3):513-9.

29 Iwata $\mathrm{T}$, Ueno $\mathrm{H}$, Itami J, Ito $\mathrm{Y}$, Inaba $\mathrm{K}$, Morizane C, et al. Efficacy of radiotherapy for primary tumor in patients with unresectable pancreatic neuroendocrine tumors. Jpn J Clin Oncol. 2017;47(9):826-31.

30 van Leeuwen CM, Oei AL, Crezee J, Bel A, Franken NAP, Stalpers LJA, et al. The alfa and beta of tumours: a review of parameters of the linear-quadratic model, derived from clinical radiotherapy studies. Radiat Oncol. 2018; 13(1):96.

31 Ahmed KA, Caudell JJ, El-Haddad G, Berglund AE, Welsh EA, Yue B, et al. Radiosensitivity differences between liver metastases based on primary histology suggest implications for clinical outcomes after stereotactic body radiation therapy. Int J Radiat Oncol Biol Phys. 2016;95(5):1399-404.

32 Chen K, Whitman J, Paciorek A, Nakakura EK, Fidelman N, Feng MU-S, et al. Outcomes after high-dose radiation in management of neuroendocrine neoplasms. J Clin Oncol. 2020;38(4 Suppl 1):616.
33 Bignardi $\mathrm{M}$, Huscher A, Centurioni M, Colangione MM, Barbieri D, Galelli M, et al. EP1270: SBRT for liver metastases from low grade neuroendocrine tumors. Radiother Oncol. 2016;119:S598-9. Elsevier.

34 Kim H, Gill B, Beriwal S, Huq MS, Roberts MS, Smith KJ. Cost-effectiveness analysis of stereotactic body radiation therapy compared with radiofrequency ablation for inoperable colorectal liver metastases. Int J Radiat Oncol Biol Phys. 2016;95(4):1175-83.

35 Jackson WC, Tao Y, Mendiratta-Lala M, Bazzi L, Wahl DR, Schipper MJ, et al. Comparison of stereotactic body radiation therapy and radiofrequency ablation in the treatment of intrahepatic metastases. Int J Radiat Oncol Biol Phys. 2018;100(4):950-8.

36 Garcia-Carbonero R, Garcia-Figueiras R, Carmona-Bayonas A, Sevilla I, Teule A, Quindos M, et al. Imaging approaches to assess the therapeutic response of gastroenteropancreatic neuroendocrine tumors (GEPNETs): current perspectives and future trends of an exciting field in development. Cancer Metastasis Rev. 2015;34(4):823-42.

37 Sahu S, Schernthaner R, Ardon R, Chapiro J, Zhao Y, Sohn JH, et al. Imaging biomarkers of tumor response in neuroendocrine liver metastases treated with transarterial chemoembolization: can enhancing tumor burden of the whole liver help predict patient survival? Radiology. 2017;283(3):883-94.
38 Gomez DR, Blumenschein GR Jr, Lee JJ, Hernandez M, Ye R, Camidge DR, et al. Local consolidative therapy versus maintenance therapy or observation for patients with oligometastatic non-small-cell lung cancer without progression after first-line systemic therapy: a multicentre, randomised, controlled, phase 2 study. Lancet Oncol. 2016; 17(12):1672-82.

39 Palma DA, Olson R, Harrow S, Gaede S, Louie AV, Haasbeek C, et al. Stereotactic ablative radiotherapy versus standard of care palliative treatment in patients with oligometastatic cancers (SABR-COMET): a randomised, phase 2, open-label trial. Lancet. 2019; 393(10185):2051-8.

40 Colaco RJ, Decker RH. Stereotactic radiotherapy in the treatment of primary bronchial carcinoid tumor. Clin Lung Cancer. 2015;16(2): e11-4.

41 Singh D, Chen Y, Cummings MA, Milano MT. Inoperable pulmonary carcinoid tumors: local control rates with stereotactic body radiotherapy/hypofractionated RT with imageguided radiotherapy. Clin Lung Cancer. 2019; 20(3):e284-e90.

42 Albanus DR, Apitzsch J, Erdem Z, Erdem O, Verburg FA, Behrendt FF, et al. Clinical value of (6)(8)Ga-DOTATATE-PET/CT compared to stand-alone contrast enhanced CT for the detection of extra-hepatic metastases in patients with neuroendocrine tumours (NET). Eur J Radiol. 2015;84(10):1866-72.

43 Naswa N, Sharma P, Kumar A, Nazar AH, Kumar R, Chumber S, et al. Gallium-68-DOTA-NOC PET/CT of patients with gastroenteropancreatic neuroendocrine tumors: a prospective single-center study. AJR Am J Roentgenol. 2011;197(5):1221-8. 